\title{
FUNGICIDES IN THE CONTROL OF PHYTOPHTYORA DISEASE OF RUBBER IN SRI LANKA
}

\author{
H.G. JAYATISSA ${ }^{1}$, N.I.S. LIYANAGE ${ }^{2^{*}}$ AND R.L.C. WIJESUNDERA ${ }^{1 * *}$ \\ ${ }^{1}$ Department of Botany, University of Colombo, Colombo 3. \\ 2 Department of Plant Pathology, Rubber. Research Institute, Agalauatta.
}

(Date of receipt : 30 June 1993)
(Date of acceptance : 20 December 1993)

\begin{abstract}
Ahstract: Nine fungicides were screened for activity against bark rot of rubber caused by Phytophthora meadii. Three fungicides, (F: 523, TLT and KWG 0599) proved to be effective in controlling the disease. Further, in addition to currently recommended fungicides Brunolinum and Sandofan, Aliette [at 5\%] and the testec fungicides belonging to the pthalimide group, especially Folpet 40FL [at 5\%], were effective in controlling lesion formation on petioles and stems of the rubber plant under field conditions. The resuits also demonstrated the prophylactic importance of thesc fungicides in reducing disease incidence wher the environmental conditions become favourable for infection.
\end{abstract}

\section{INTRODUCTION}

Hevea brasiliensis is a major plantation crop of Sri Lanka, prcducing about 180,000 tons of rubber per year. The rubber tree is affected by various diseases caused by two species of Phytophthora, P. meadii and P. palmivora resulting in abnormal lea fall, pod rot, shoot die back and the panel diseases - bark rot and canker. The diseases occur in varying degrees of severity and infection of the panel with attendant economic loss. In Sri Lanka, the disease is primarily caused by P. meadii. ${ }^{1,2}$

Control measures are not employed in Sri Lanka against the leaf fall, pod rot and die back phase of the disease as it is not economical. However, routine protection is given to the tapping panel to prevent infection by applying selected fungicides. ${ }^{3}$ In Sri Lanka until 1987, Antimucin (Phenyl mercuric acetate), Fylomac (Tetradecyl pyridinium bromide) and Difolotan (Captofol) were used to control this disease. ${ }^{1}$ At present, Antimucin is banned because of its long term toxic effects, Fylomac is out of production and Difolotan has been discontinued due to its carcinogenic properties. As a result, the rubber grower is now dependent on Brunolinum plantarum (non-systemic) and Sandofan paste, which have been recommended after experimentation. ${ }^{1,3}$ The latter is a systemic fungicide that is very expensive and hence uneconomical to use prophylactically.

* Present address: University of S. Pacific, W. Samoa.

** Corresponding author.

Publication of this article does not constitute an endorsement by NARESA of the use of any of the products mentioned in the article. 
There is therefore an urgent need to select effective, cheap fungicides for both as prophylactic and curative use. In this investigation, the following fungicides were screened to evaluate their efficacy in controlling $P$. meadii: three from the pthalimide group (Folpet 48KR, TKH and 40FL), PP523 (hexaconazole), Alietie (ethyl phosphate), TILT-A 6997 KEC250 (propiconazole) and KWG 0599 (bitertanol). The fungicides Brunolinum and Sandofan were used for comparison.

\section{METHODS AND MATERIALS}

Fungal culture: Phytophihora meadii (Plant Pathology Department, Rubber Research Institute, Agalavatte) was maintained on lima bean agar (LBA) at room temperature, $28 \pm 2^{\circ} \mathrm{C}^{2}$

[A]. Assessment of contact fungicidal activity: To assess the contact fungicidal activity two seperate experiments were carried out using two concentrations of the fungicides recommended by the manufacturers.

(i) In this experiment the rates of each fungicide were based on the lower rates recommended by the manufacturers. The different treatments included, TILT EC 250 (25 ppm), Aliette (2\%), PP523 (20ppm), KWG 0599 (1\%), Folpet 40FL (5\%), Folpet 48R (5\%), Folpet TKH (5\%). Brunolinum plantarum (15\%), Sandofan paste (neat) and sterile distilled water were used as controls. A modified filter paper disc method was used ${ }^{4}$. Sterile filter paper discs $(0.6 \mathrm{~cm}$ diameter) were dipped in the solution or suspensions of the fungicides, air dried and placed on LBA plates. Each treatment was replicated three times and each plate had three discs of fungicide treated filter paper. Discs of $P$. meadii were removed from the leading edge of a 5 -day old culture of the fungus growing on $9 \mathrm{~cm}$ petri dishes containing $15 \mathrm{ml}$ LBA. The inoculum plugs were placed on the fungicide treated filter paper discs maintained on LBA plates in such a way that the surface of the mycelium was in contact with the treated paper disc. The LBA plates containing the treated filter paper discs and fungal plugs were incubated at $28 \pm 22^{\circ} \mathrm{C}$.

(ii) The above experiment was repeated by re-testing the fungicides which did not completely inhibit fungal growth in the first experiment by using the higher concentrations suggested by the manufacturers. The treatments included Aliette (5\%), Folpet 40FL (10\%), KWG 0599 (5\%), PP $523(80 \mathrm{ppm})$ and TILT EC 250 (50 ppm). Sterile distilled water was used as the control.

[B]. Assessment of the efficacy of the fungicides as a prophylactic treatment using petioles of rubber: The fungicides were examined at the following concentrations, TILT EC 250 (50ppm), Aliette (5\%), PP523 (80ppm),KWG 0599 (5\%), Folpet 40FL(10\%), Folpet 48R (5\%), Folpet TKH (5\%). Brunolinum plantarum (15\%), Sandofan paste (neat) and sterile distilled water were used as controls. The higher concentration recommended was used for all fungicides except for those fungicides which totally inhibited growth in the first experiment described above. Tender 
petioles (12-14 days old) from clone PB 86 were removed from plants grown in bud wood nursery. The cut ends of the petioles were dipped in molten wax and each preparation of the fungicide was applied to the surface of the petiole using a hair brush, leaving about $1 \mathrm{~cm}$ untreated at both ends. Petioles were thereafter air dried and placed in trays lined with moist filter paper. Each petiole was inoculated at the centre with a strip of cotton wool $(1.5 \times 0.5 \mathrm{~cm})$ soaked in $0.1 \mathrm{ml}$ of inoculum from a zoospore suspension $\left(10^{5}\right.$ zoospore/ml sterile distilled water). Length of lesions were measured 5 days following incubation at room temperture $28 \pm 2^{\circ} \mathrm{C}$. Ten petioles were used for each experiment.

[C]. Efficacy of the Pungicides as a prophylactic treatment against bark rot disease: Six fungicides, Folpet $48 \mathrm{R}$, Folpet TKH, Folpet 40L, Aliette, Brunolinum and Sandofan were selected based on the results of the earlier experiments. Sterile distilled water, Brunolinum and Sandofan were used as the controls. Thirty trees (about 2 year old) of clone PB 86 (susceptible to bark rot) having stems of uniform size (10 cm circumference) were chosen. On each stem at about $1.5 \mathrm{~m}$ above soil level, an area of bark $30 \mathrm{~cm}$ long and encompossing the entire circumference of the tree was slightly scraped with a hard brush. Six trees each were applied with the fungicides Folpet $48 \mathrm{R}$, Folpet TKH and Folpet $40 \mathrm{FL}$ at $2.5 \%$ and $5 \%$, Brunolinum at $15 \%$, Sandofan (neat) and Aliette at $5 \%$ on the scraped areas 4 times, at 7-day intervals using a hair brush. One week after the final application of the respective treatment, the trees were inoculated with a zoospore suspension of the fungus as described under inoculation of trees. ${ }^{4}$ Eleven weeks after inoculation the inoculated area was exposed and the area of lesion development on the surface of the wood was traced on drawing paper and then measured with an area meter.

[D]. Efricacy of fungicides as a curative treatment: Sixty three trees of rubber (15-year old trees) were selected from a plantation infested heavily with the disease and showing typical symptoms of bark rot. The damage was assessed prior to applying the fungicides by counting the number of depressions and measuring the length of each depression. The fungicides Folpet $48 \mathrm{R}$ (5\%), Folpet TKH (5\%), Folpet 40FL (5\%), Brunolinum (15\%), Sandofan (neat) and Aliette (5\%) were applied at 7-day intervals for 4 weeks to unscraped bark covering an area of $25 \mathrm{~mm}$ width above the tapping panel. Nine trees were used for each experiment. Nine, untreated infected trees were left as controls. Tapping of all trees was done as usual. Number and length of new and old vertical depressions on the panels of untreated trees were measured weekly and on treated trees one week after the final application of fungicide.

[E]. Inoculation of trees: A plug of $2 \mathrm{~cm}$ diameter was removed from the bark; the exuded latex was allowed to coagulate and was removed using cotton wool. A plug of $2.0 \mathrm{~cm}$ sterile absorbent cotton wool previously soaked in $P$. meadii spore suspension in sterile distilled water $\left(10^{4}\right.$ spores $\left./ \mathrm{ml}\right)$ was inserted in to the cavity. This area was covered with adhesive tape to prevent drying. ${ }^{4}$ 
[F]. Preparation of spore suspension: Six-day old cultures of $P$. meadii on LBA were scraped with a sterile scalpel and the scrapings were transferred to $50 \mathrm{ml}$ of sterile distilled water in a sterile beaker. The spore suspension was kept at $15^{\circ} \mathrm{C}$ for $20 \mathrm{~min}$ and thereafter exposed to room temperature for a further $15 \mathrm{~min}$ to enhance release of spores. The suspension was then filtered through a double layer of muslin and concentration was adjusted with sterile distilled water using a haemocytometer. ${ }^{4}$

\section{RESULTS}

[A]. Contact fungicidal activity: In the first experiment no growth of the fungus was observed in the plates treated with Brunolinum (15\%), Sandofan (neat), Folpet TKH (5\%) and Folpet $48 \mathrm{R}(5 \%)$ indicating complete efficacy. A significant difference in the mean colony diameter was observed between Aliette (2\%), Folpet $40 \mathrm{FL}(5 \%)$ treated and the control treated with distilled water. The difference was significant at both $40 \mathrm{~h}$ and $7.2 \mathrm{~h}$ (Table 1). KWG 0599, PP 523 and TILT had no significant effect on the growth of the fungus.

Table 1: Mean colony diameter $(\mathrm{mm})$ of $P$. meadii when inoculated on to sterile paper discs treated with fungicides.

\begin{tabular}{lccc}
\hline \multicolumn{1}{c}{ Fungicide } & Concentration. & $\begin{array}{c}\text { Mean colony } \\
\text { diameter }\end{array}$ \\
& & $40 \mathrm{~h}$ & $72 \mathrm{~h}$ \\
\hline Brunolinum [control] & $15 \%$ & 0 & 0 \\
Sandofan [control] & neat & 0 & 0 \\
Folpet TKH & $5 \%$ & 0 & 0 \\
Folpet 48R & $5 \%$ & 0 & 0 \\
Aliette & $2 \%$ & $14.1 \mathrm{a}$ & $26.3 \mathrm{c}$ \\
Folpet 40FL & $5 \%$ & $15.2 \mathrm{a}$ & $25.7 \mathrm{c}$ \\
KWG 0599 & $1 \%$ & $21.7 \mathrm{~b}$ & $32.8 \mathrm{~d}$ \\
PP 523 & $20 \mathrm{ppm}$ & $22.3 \mathrm{~b}$ & $33.8 \mathrm{~d}$ \\
TILT & $25 \mathrm{ppm}$ & $22.8 \mathrm{~b}$ & $34.0 \mathrm{~d}$ \\
Control [Dist. water] & - & $22.6 \mathrm{~b}$ & $34.3 \mathrm{~d}$ \\
\hline
\end{tabular}

Mean of 5 replicates.

Means in a column followed by the same letter are not significantly different at $P=0.05$.

In the second experiment where higher concentrations of the fungicides were evaluated no growth occurred in the LBA plates treated with Folpet 40 FL. Aliette at $5 \%$ also appeared promising as the colony diameter was significantly less. Even at higher concentrations KWG 0599, TILT, PP523 had no effect (Table 2). 
Table 2: Mean colony diameter $(\mathrm{mm})$ of $\bar{P}$. meadil when inoculated on to sterile paper discs treated with fungicides

\begin{tabular}{lccc}
\multicolumn{1}{c}{ Fungicide } & Concentration & \multicolumn{2}{c}{ Mean colony diameter } \\
& & $40 \mathrm{~h}$ & $72 \mathrm{~h}$ \\
\hline Folpet 40 FL & $10 \%$ & 0 & 0 \\
Aliette & $5 \%$ & $6.20 \mathrm{a}$ & $12.42 \mathrm{~b}$ \\
KWG 0599 & $5 \%$ & $20.36 \mathrm{c}$ & $31.76 \mathrm{~d}$ \\
PP 523 & $80 \mathrm{ppm}$ & $21.26 \mathrm{c}$ & $33.02 \mathrm{~d}$ \\
TILT & $50 \mathrm{ppm}$ & $21.70 \mathrm{c}$ & $33.70 \mathrm{~d}$ \\
Control [Dist.water] & - & $21.94 \mathrm{c}$ & $33.24 \mathrm{~d}$ \\
\hline
\end{tabular}

Mean of 5 replicates.

Means in a column followed by the same letter are not significantly different at $P=0.05$.

\section{Efficacy of fungicides as a prophylactic treatment}

[B]. Using petioles of rubber: Lesion development did not occur on petioles pre-treated with Sandofan, Folpet $40 \mathrm{FL}$, Aliette and Folpet 48R. On petioles pre-treated with Folpet TKH, Brunolinum and TILT lesions developed but size was significantly less than on the control. Petioles treated with KWG 0599 and PP 523 had large lesions showing no significant difference with the lesions on the controls (Table 3 ).

Table 3: Mean length $(\mathrm{mm})$ of lesions on rubber petioles 5 days after inoculation with $\boldsymbol{P}$. meadit. (Petioles were pre-treated with the fungicide before inoculation)

\begin{tabular}{lcc}
\hline \multicolumn{1}{c}{ Fungicide } & Concentration & Mean lesion length \\
\hline Sandofan & neat & 0 \\
Folpet 40FL & $10 \%$ & 0 \\
Aliette & $5 \%$ & 0 \\
Folpet 48R & $5 \%$ & 0 \\
Folpet TKH & $5 \%$ & $13.89 \mathrm{~b}$ \\
Brunolinum & $15 \%$ & $37.78 \mathrm{c}$ \\
TILT & $50 \mathrm{ppm}$ & $51.00 \mathrm{~d}$ \\
PP 523 & $80 \mathrm{ppm}$ & $65.11 \mathrm{a}$ \\
KWG 0599 & $5 \%$ & $61.67 \mathrm{a}$ \\
Control [Dist.water] & - & $81.11 \mathrm{a}$ \\
\hline
\end{tabular}

Mean of 10 replicates.

Means in a column followed by the same letter are not significantly different at $P=0.05$. 
[C]. Using nursery plants: The lesion area was lowest on plants pre- treated with Aliette 5\%: The highest lesion area was observed on plants treated with Brunolinum. However, all lesion areas on fungicide treated plants were significantly lower than on the control plants (Table 4).

Table 4: Mean lesion area $\left(\mathrm{cm}^{2}\right)$ on stems of nursery plants 11 weeks after inoculation with $P$. meadii (the stems were pre-treated with fungicides before inoculation)

\begin{tabular}{lcc}
\hline Fungicide & Concentration & Mean lesion area \\
\hline Aliette & $5 \%$ & 2.3 \\
Sandofan & neat & 5.3 \\
Folpet TKH & $5 \%$ & 6.3 \\
& $2.5 \%$ & 7.0 \\
Folpet 48R & $5 \%$ & 8.0 \\
& $2 \%$ & 8.3 \\
Folpet 40FL & $5 \%$ & 8.6 \\
& $2.5 \%$ & 8.9 \\
Brunolinum & $15 \%$ & 9.0 \\
Control & - & 15.0 \\
\hline
\end{tabular}

Mean of 6 replicates.

All values differed significantly from the control at $P=0.05$.

[D]. Effect of fungicides as a curative: The number of depressions on the bark decreased after the application of Folpet 40FL and Aliette (Table 5). A slight increase occurred with other fungicides, but less than in the controls. The length of depressions increased in all treatments, but the increase was less with Brunolinum, Aliette, Folpet 48R and Folpet TKH (Table 5).

\section{DISCUSSION}

The fungicides KWG 0599, PP 523 and TILT had no significant effect in suppresing the growth of the fungus. All other fungicides used in the investigation, proved to be effective. The effective fungicides (Folpet 40L, Folpet 48R, Folpet TKH and Aliette) when applied prior to inoculation with the pathogen, significantly reduced development of lesions in the petioles of mature rubber plants as well as on nursery plants. This emphasizes the importance of prophylactic treatment to reduce or prevent occurrence of bark rot when the inoculum is present in the field.

Amongst the listed fungicides only Aliette and Folpet 40FL were able to decrease the number of depressions when applied to naturally infected plants. However, the observed decrease was only marginal, as both these fungicides, as 
Table 5: Lesion development on naturally infected trees (PB 86) after fungicidal treatment

\begin{tabular}{lcrrrr}
\hline Fungicide & Concentration & \multicolumn{2}{c}{$\begin{array}{c}\text { Mean number of } \\
\text { depressions }\end{array}$} & \multicolumn{2}{c}{$\begin{array}{c}\text { Mean length of } \\
\text { depressions } \\
(\mathrm{mm})^{*}\end{array}$} \\
\hline Brunolinum & $15 \%$ & $\mathrm{a}$ & $\mathrm{b}$ & $\mathrm{a}$ & $\mathrm{b}$ \\
Sandofan & neat & 9.6 & 5.7 & 9.9 & 10.3 \\
Aliette & $5 \%$ & 6.1 & 10.3 & 7.5 & 10.5 \\
Folpet 48R & $5 \%$ & 5.7 & 8.6 & 8.3 & 9.5 \\
Folpet TKH & $5 \%$ & 5.2 & 7.4 & 10.2 & 11.5 \\
Folpet 40FL & $5 \%$ & 6.6 & 4.5 & 8.9 & 9.5 \\
Control & - & 4.7 & 13.1 & 8.4 & 11.1 \\
\hline
\end{tabular}

Mean from 9 trees.

a - before fungicide treatment

$b$ - after fungicide treatment

in the case of other tested ones, failed to limit the expansion of the length of the depressions. Hence, the effect of the fungicides appear to be more prophylactic in nature rather than curative.

The results of this investigation indicate that in addition to the currently recommended fungicides Brunolinum and Sandofan, the newer fungicides of the pthalimide group, especially Folpet $40 \mathrm{FL}$, and Aliette, are effective against the bark rot fungus. This study also demonstrates the potential to prevent bark rot by applying suitable fungicides during periods favourable to the pathogen.

\section{References}

1. Liyanage N.I.S. (1987). Phytophthoras on rubber: Pathogenecity, taxonomy, survival and disease control. Ph.D. Thesis, University of London.

2. Peries O.S., Liyanage A. de S. \& Liyanage N.I.S. (1979). A comparative study of the nutrition of Phytophthora meadii and Phytophthora palmivora. Joumal of the Rubber Research Institute, Sri Lanka. 56: 1-8.

3. Liyanage A. de S. (1985). Diseases of rubber and their control. Bulletin of the Rubber Research Institute, Sri Lanka. 20: 5-9.

4. Peiris O.S., Sivapalan V. \& Dantanarayana D.M. (1962). Methods used by the Rubber Research Institute for testing water miscible fungicides for the control of bark rot of Hevea. Journal of the Rubber Research Institute of Ceylon 38: 57-61. 